\title{
Quantitative determination of hippuric and m-methylhippuric acids in urine by high-speed liquid chromatography
}

\author{
H. MATSUI, M. KASAO, AND S. IMAMURA \\ From the Department of Hygiene, School of Medicine, Gunma University, Maebashi, Japan
}

ABSTRACT High-speed liquid chromatography employing an ultraviolet photometric detector has been applied to the simultaneous determination of hippuric and m-methylhippuric acids in urine. Reversed-phase partition chromatography is carried out on a $\mu$ Bondapak $\mathrm{C}_{18}$ column with methanol-water as the eluent system. This method obviates the necessity for isolation or reaction of these acids before assay. The only pretreatment necessary is extraction of samples with ethyl acetate. A linear relationship is obtained between the peak heights and the hippuric or m-methylhippuric acid concentrations. Mean recovery of hippuric and m-methylhippuric acids in urine is $99.8 \%$ and $99.3 \%$ respectively. The determination of hippuric acid by this method gives lower concentrations in normal urine than does the colorimetric method of Umberger and Fiorese (1963).

It has been observed that the concentration of hippuric and m-methylhippuric acids in urine correlates well with exposure of the subject to toluene and $\mathrm{m}$ xylene (Pagnotto and Lieberman, 1967; Ikeda and Ohtsuji, 1969; Ogata et al., 1970).

Many methods have been used for the determination of these metabolites using colorimetry (Gaffney et al., 1954; Umberger and Fiorese, 1963), fluorometry (Ellman et al., 1961), and ultraviolet spectrophotometry (Pagnotto and Lieberman, 1967). However, some constituents in the urine interfere with the assay and have to be removed by liquid/ liquid extraction and chromatography (Ogata et al., 1962). Where the urine contains both hippuric and m-methylhippuric acids, they can be separated using paper or thin-layer chromatography, with subsequent conversion to azlactones and assay of each constituent (Ogata et al., 1969). Recently, a gas-liquid chromatographic method (Buchet and Lauwerys, 1973) has been reported based on the conversion of hippuric and m-methylhippuric acids for their specific determination.

This report describes a high-speed liquid chromatographic method which obviates the necessity for isolating these acids or for converting them before assay.

Received for publication 30 June 1976 Accepted for publication 16 June 1977

\section{Materials and methods}

CHROMATOGRAPHIC SYSTEM AND

OPERATING CONDITIONS

A Waters ALC 202 high-speed liquid chromatograph equipped with a low-pressure mercury $(254 \mathrm{~nm})$ photometric detector was used in this study. Samples were introduced on to the column through a Waters U6K septumless injector. A $\mu$ Bondapak $C_{18}$ prepacked column (Waters Assoc.), which is a reversed-phase column $(30 \mathrm{~cm} \times 4 \mathrm{~mm}$ I.D. $)$ containing small-diameter porous silica particles chemically bonded to aliphatic hydrocarbon groups, was used. The column was eluted at $1 \mathrm{ml} / \mathrm{min}$ with methanol and $0.01 \mathrm{~mol} / 1 \mathrm{KH}_{2} \mathrm{PO}_{4}$ containing $0.5 \%$ acetic acid (20/80 by volume) at room temperature. Injections were performed with a $10 \mu \mathrm{l}$ syringe (Hamilton $701 N)$.

\section{URINE TREATMENT}

Extraction of hippuric and m-methylhippuric acids from urine was carried out according to the method described by Ogata et al. (1969). One millilitre of urine, $0.04 \mathrm{ml}$ of concentrated $\mathrm{HCl}, 0.3 \mathrm{~g}$ of $\mathrm{NaCl}$ and $4.0 \mathrm{ml}$ of ethyl acetate were shaken vigorously in a glass-stoppered tube for two minutes. After centrifugation for five minutes at $2500 \mathrm{rpm}, 0.2 \mathrm{ml}$ of the supernatant ethyl acetaie was transferred to a test tube and evaporated to dryness on a water bath 
at $70^{\circ} \mathrm{C}$. The residue was dissolved in $0.2 \mathrm{ml}$ distilled water and $4 \mu \mathrm{l}$ aliquots were injected into the chromatograph.

\section{CALIBRATION CURVES}

Standard solutions containing hippuric acid (Tokyo Kasei, Japan) and m-methylhippuric acid (Tokyo Kasei, Japan) were made up in distilled water to give a range of concentrations of $2-10 \mathrm{mg} / \mathrm{ml}$. One volume of each solution was mixed with nine volumes of water or urine, and these were treated as described above. Peak heights were plotted against the concentrations of hippuric or m-methylhippuric acid.

\section{COLORIMETRIC DETERMINATION OF \\ HIPPURIC ACID IN URINE}

Urinary hippuric acid was estimated by the procedure of Umberger and Fiorese (1963) with slight modifications. The samples were treated as indicated under 'urine treatment'. The residue was mixed with $0.5 \mathrm{ml}$ of pyridine and $0.2 \mathrm{ml}$ of benzenesulphonyl chloride. After the mixture had stood for $\mathbf{3 0}$ minutes it was diluted with $3.0 \mathrm{ml}$ of ethanol and the absorbance was measured at $410 \mathrm{~nm}$ against a pyridinebenzenesulphonyl chloride blank on a Hitachi Perkin-Elmer 139 UV-VIS spectrophotometer. Blank and hippuric acid standards were treated by the same procedure.

\section{Results}

\section{CHROMATOGRAM}

The chromatograms obtained for sample extracts are shown in Figs. 1a-c, and hippuric and m-methylhippuric acids were found to be separated in the same run. Hippuric acid but not m-methylhippuric acid was shown to be present in the urine of a person who had not been exposed to solvent (Fig. 1c).

Several mobile phases were evaluated for the liquid chromatographic development of these acids in water and in urine. Satisfactory development was observed with mixtures of methanol and water $\left(0.01 \mathrm{~mol} / 1 \mathrm{KH}_{2} \mathrm{PO}_{4}+0.5 \%\right.$ (v/v) acetic acid).

LINEARITY OF CALIBRATION CURVES

As the peaks of the acids were well resolved and symmetrical, peak heights were used as measures of concentration. As Fig. 2 indicates, the peak heights showed a linear relationship with the hippuric or $\mathrm{m}$ methylhippuric acid concentrations. Furthermore, the linearity and the slope of calibration curves were not influenced by the addition of urine to the aqueous standard solutions. Recoveries for hippuric and $\mathrm{m}$ methylhippuric acids were $99.8 \% \pm 6.6 \%$ (mean \pm standard deviation) and $99 \cdot 3 \% \pm 6 \cdot 2 \%$, respectively.

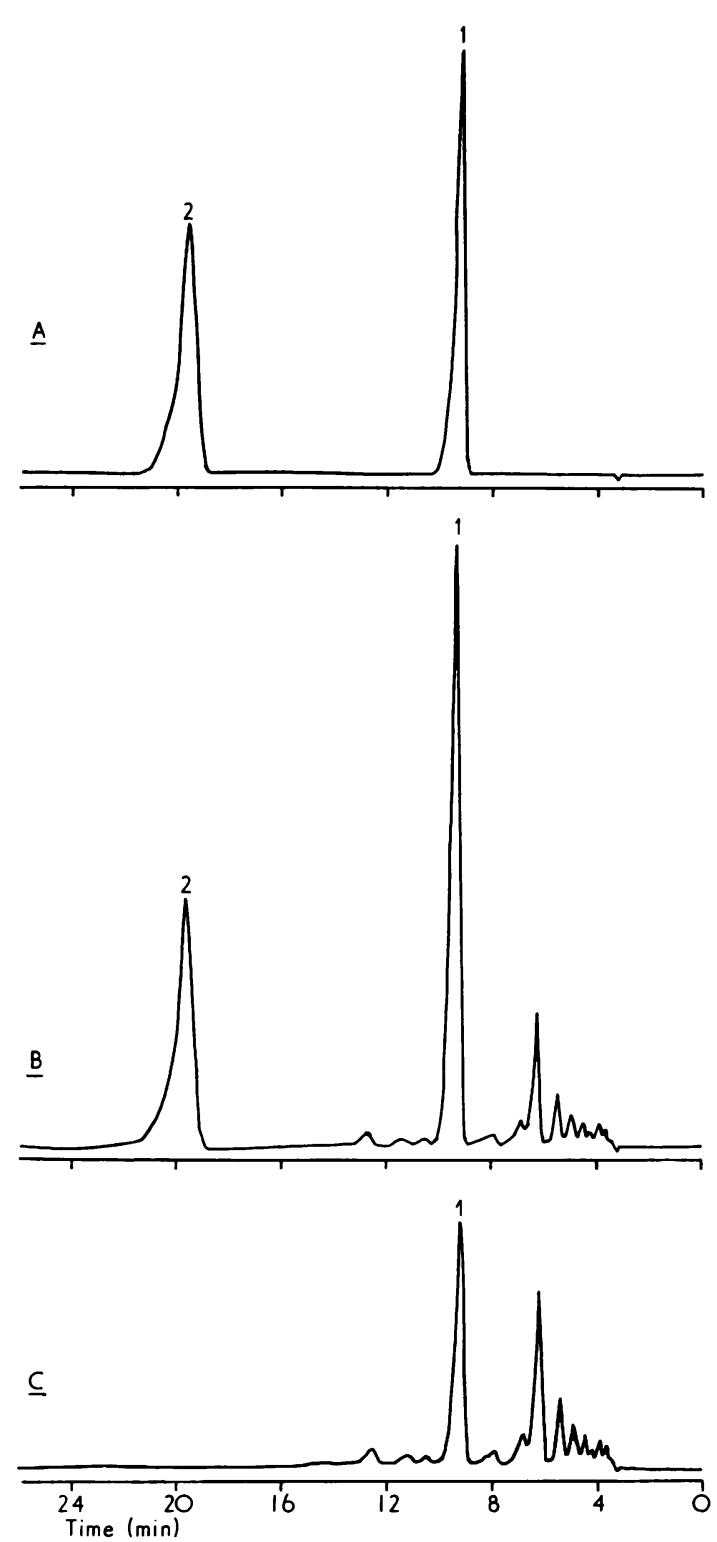

Fig. 1 Chromatograms of sample extracts. a) standard aqueous solution; b) urine supplemented with standard acids; c) control urine. 1 = hippuric acid; $2=$ m-methylhippuric acid.

COMPARISON OF COLORIMETRIC AND LIQUID CHROMATOGRAPHIC METHODS FOR URINARY HIPPURIC ACID

The urine of 39 subjects with no occupational exposure to solvents was analysed both by liquid 
chromatography and by the colorimetric method of Umberger and Fiorese (1963). The results are compared in Fig. 3. The values obtained by liquid chromatography were lower than those found by the colorimetric method. This suggests that in the colorimetric determination of hippuric acid, other urinary constituents may interfere. However, there was a good correlation between the concentration of hippuric acid in urine as measured by these two methods. The regression line is: $y=0.4068 \mathrm{x}-0.0290$, where $y$ is hippuric acid concentration $(\mathrm{mg} / \mathrm{ml})$ as obtained by liquid chromatography and $\mathrm{x}$ is that obtained by the colorimetric method. The correlation coefficient, $r$, is $0.939(n=39)$.

\section{Discussion}

Several methods using spectrophotometric procedures have been described for the determination of hippuric and m-methylhippuric acids in human urine. However, in most of these methods there is interference by various compounds present in normal urine and by metabolites of certain drugs. Furthermore, when the urine contains both hippuric acid and m-methylhippuric acid, the acids must be separated before spectrophotometric measurement.

In the present investigation using high-speed liquid chromatography, simultaneous determination of hippuric and $\mathrm{m}$-methylhippuric acids in urine

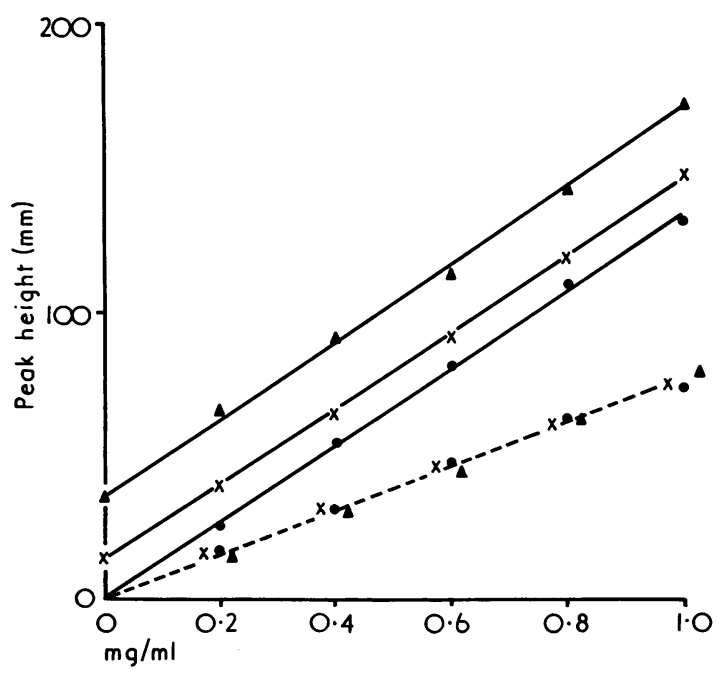

Fig. 2 Calibration curves for hippuric acid (solid line) and $m$-methylhippuric acid (dotted line). $=$ aqueous standard solution; $\times$ and $\boldsymbol{\Delta}=$ urine supplemented with standard acids.



Fig. 3 Comparison of results for hippuric acid in urine: liquid chromatographic vs. colorimetric methods.

can be accomplished. This method does not require any isolation or conversion of these acids before assay.

The study presented here suggests that hippuric acid in urine is determined with specificity by highspeed liquid chromatography. On the other hand, the colorimetric method of Umberger and Fiorese (1963) which is not specific for hippuric acid gives higher concentrations than those by liquid chromatography. These data are similar to those reported by Porter et al. (1975). In their study, hippuric acid in normal urine determined by gas-liquid chromatography accounted for approximately one-third of that measured by the fluorescent method (Ellman et al., 1961) which lacks specificity.

\section{References}

Buchet, J. P., and Lauwerys, R. R. (1973). Measurement of urinary hippuric and m-methylhippuric acids by gas chromatography. British Journal of Industrial Medicine, 30, 125-128.

Ellman, G. L., Burkhalter, A., and LaDou, J. (1961). A fluorometric method for the determination of hippuric acid. Journal of Laboratory and Clinical Medicine, 57, 813-818.

Gaffney, G. W., Schreier, K., DiFerrante, N., and Altman, K. I. (1954). The quantitative determination of hippuric acid. Journal of Biological Chemistry, 206, 695-698.

Ikeda, M., and Ohtsuji, H. (1969). Significance of urinary hippuric acid determination as an index of toluene exposure. British Journal of Industrial Medicine, 26, 244-246.

Ogata, M., Sugiyama, K., and Moriyasu, H. (1962). Studies on poisoning. IV. Toluene concentration in air and urinary hippuric acid measured by paperchromatography and mass 
screening examination method. Acta Medicinae Okayama, 16, 283-292.

Ogata, M., Tomokuni, K., and Takatsuka, Y. (1969). Quantitative determination in urine of hippuric acid and $\mathrm{m}$ - or p-methylhippuric acid, metabolites of toluene and $\mathrm{m}$ - or p-xylene. British Journal of Industrial Medicine, 26, 330-334.

Ogata, M., Tomokuni, K., and Takatsuka, Y. (1970). Urinary excretion of hippuric acid and $\mathrm{m}$ - or p-methylhippuric acid in the urine of persons exposed to vapours of toluene and $\mathrm{m}$ - or p-xylene as a test of exposure. British Journal of Industrial Medicine, 27, 43-50.
Pagnotto, L. D., and Lieberman, L. M. (1967). Urinary hippuric acid excretion as an index of toluene exposure. American Industrial Hygiene Association Journal, 28, 129. 134.

Porter, R. D., Cathcart-Rake, W. F., Wan, S. H., Whittier, F. C., and Grantham, J. J. (1975). Secretory activity and aryl acid content of serum, urine, and cerebrospinal fluid in normal and uremic man. Journal of Laboratory and Clinical Medicine, 85, 723-733.

Umberger, C. J., and Fiorese, F. F. (1963). Colorimetric method for hippuric acid. Clinical Chemistry, 9, 91-96.

\section{The August 1977 issue}

\section{THE AUGUST 1977 ISSUE CONTAINS THE FOLLOWING PAPERS}

A mortality study among workers in an English asbestos factory J. PETO, R. DOLL, S. V. HOWARD, L. J. KINLEN, AND H. C. LEWINSOHN

Insulation workers in Belfast. A further study of mortality due to asbestos exposure (1940-75) P. C. ELMES AND M. J. C. SIMPSON

An investigation into the health of kapok workers c. G. URAGODA

Farmer's lung in a group of Scottish dairy farms V. E. WARDROP, W. BLYTH, AND I. W. B. GRANT

Chronic pulmonary function loss from exposure to toluene diisocyanate D. H. WEGMAN, J. M. PETERS, L. PAGNOTTO, AND L. J. FINE

Nasal cancers, symptoms and upper airway function in woodworkers H. C. ANDERSEN, I. ANDERSEN, AND J. SOLGAARD
Heavy metal pollution among autoworkers. I. Lead J. ClAUSEN AND S. C. RASTOGI

Heavy metal pollution among autoworkers. II. Cadmium, chromium, copper, manganese and nickel J. CLAUSEN AND S. C. RASTOGI

Cadmium metabolism in man $\mathrm{H}$. WELINDER, $\mathrm{s}$. SKERFVING, AND O. HENRIKSEN

Simultaneous determination of toluene and xylene metabolites in urine by gas chromatography J. $R$. CAPEROS AND J. G. FERNÁNDEZ

Book reviews

Notices

Information section

Copies are still available and may be obtained from the PUBLISHING MANAGER, BRITISH MEDICAL ASSOCIATION, TAVISTOCK SQUARE, LONDON, WC1H 9JR, price $£ 3 \cdot 75$, (USA \$9.20) including postage 